\title{
Protective Effect of Allium tuberosum Extract on Vascular Inflammation in Tumor Necrosis Factor- $\alpha$-induced Human Vascular Endothelial Cells
}

\author{
Haeng Jeon Hur, Ae Sin Lee \\ Korea Food Research Institute, Wanju, Korea
}

\begin{abstract}
Background: Endothelial adhesion molecule expression induced by pro-inflammatory cytokine plays an important role in vascular endothelial cell injury, leading to vascular disease. Allium tuberosum (AT), which is used as a functional food, has a thrombolytic effect. It contains vitamin A, vitamin C, carbohydrate, calcium, iron, and phosphorus. There are many carotenes that turn into vitamin $A$ in the body. Also, it helps blood circulation and stimulates metabolism. The purpose of the this study was to estimate the anti-inflammatory effects of the AT extract.

Methods: Human vascular endothelial cells were pre-treated with $100 \mu \mathrm{g} / \mathrm{mL}$ AT extract for 30 minutes and subsequently co-treated with TNF- $\alpha(10 \mathrm{ng} / \mathrm{mL})$ and AT extract $(100 \mu \mathrm{g} / \mathrm{mL})$ for 1,4 , and 6 hours. After treatment, the cells were lysed and used for quantitative reverse transcription $P C R$, Western blot analysis, and monocyte adhesion assay.

Results: We examined the effect of the AT extract on inflammatory gene expression in TNF- $\alpha$-induced human umbilical vein endothelial cells (HUVECS). The extract reduced the expression levels of mRNA and protein of intercellular adhesion molecule (ICAM)-1 and vascular cell adhesion molecule (VCAM)-1 in TNF- $\alpha$-stimulated HUVECs. It also inhibited the TNF- $\alpha$-induced phosphorylation of the NF- $\mathrm{B} B$ p65 subunit and degradation of $1 \kappa B \alpha$. Furthermore, the AT extract prevented the increased adhesion capacity of monocyte to TNF- $\alpha$-stimulated vascular endothelial cells by reducing ICAM-1 and VCAM-1 expression.

Conclusions: The AT extract has preventive and anti-inflammatory effect against vascular disease and has potential for supporting prevention against the early process of atherosclerosis.

(J Cancer Prev 2017;22:228-233)
\end{abstract}

Key Words: Allium tuberosum extract, Vascular cell adhesion molecule-1, Intercellular adhesion molecule-1, Inflammation, NF-kappa B

\section{INTRODUCTION}

Allium tuberosum (AT), a perennial plant belonging to the Liliaceae family, has diverse dietary phytochemicals with known antioxidant properties. ${ }^{1}$ AT is used as a functional food for its antitumor, anti-inflammatory, nerve protective, and antioxidant activities; nine compounds isolated from its root were identified as 4,8-dihydroxyacetophenone-8-O-ferulate, 4,8-dihydroxyacetophenone, buddlenol D, tianshic acid, daucosterol, and linoleic acid. $^{2}$

Inflammation is an immune mechanism that is rapidly activated by various stimuli to protect the body against physical or chemical substances, bacterial infections, and immunological events. The inflammatory reaction is divided into acute and chronic inflammation. In acute inflammation, the reaction lasts for several days to weeks and causes symptoms, such as erythema, fever, pain, and swelling, whereas chronic inflammation is a state that persists sometimes over several years to decades. Inflammation is accompanied by histological changes, such as cell invasion, fibroblast and capillary proliferation, fibrosis due to increase in connective tissue mass, and tissue destruction. In particular, interferon-gamma, TNF- $\alpha$, interleukin-1 $\beta$ (IL-1 $\beta$ ), nitric oxide, and prostaglandin E2 are well known major inflammatory agents in addition to common immune factors such as

Received December 5, 2017, Revised December 11, 2017, Accepted December 11, 2017

Correspondence to: Ae Sin Lee

Korea Food Research Institute, 245 Nongsaengmyeong-ro, Iseo-myeon, Wanju 55365, Korea

Tel: +82-63-219-9411, Fax: +82-63-219-9876, E-mail: aslee@kfri.re.kr, ORCID: Ae Sin Lee, http://orcid.org/0000-0003-2685-1826

Copyright (C) 2017 Korean Society of Cancer Prevention

(c) This is an Open Access article distributed under the terms of the Creative Commons Attribution Non-Commercial License (http://creativecommons.org/licenses/by-nc/4.0) which permits unrestricted non-commercial use, distribution, and reproduction in any medium, provided the original work is properly cited. 
IL-6, a chemokine. ${ }^{3}$ TNF- $\alpha$ increases the expression of intercellular adhesion molecule-1 (ICAM-1) on epithelial and endothelial cells, regulation of which may be controling inflammation. ${ }^{4 \cdot 6}$ Secreted TNF- $\alpha$ activates macrophages and neutrophils to secrete oxidants, such as superoxide anion, hydroxyl radicals, proteolytic enzymes, and IL- 1 and IL- 6 . In addition, TNF- $\alpha$ is known to enhance the permeability of vascular endothelial cells to promote edema. ${ }^{7.8}$

In this study, we investigated whether AT extract regulates the expression of TNF- $\alpha$-induced expression of ICAM- 1 and vascular cell adhesion molecule (VCAM)-1 and the adhesion of human monocytes to the vascular endothelial cells. We also investigated the signaling mechanism that regulates the inhibitory effect of the AT extract on adhesion molecule expression in human umbilical vein endothelial cell (HUVEC).

\section{MATERIALS AND METHODS}

\section{Preparation of the Allium tuberosum extract}

AT was purchased from a local market, Seongnam, Korea. For extraction, AT was dissolved in a 10 -fold volume of $70 \%$ ethanol with shaking for 24 hours at $25^{\circ} \mathrm{C}$, and precipitates were removed by centrifugation at $8,000 \times g$ for 30 minutes. The supernatants were dried using a freeze dryer. The AT extract was dissolved in dimethyl sulfoxide and used to treat HUVECs.

2. Materials and cell culture

Antibodies against ICAM-1, VCAM-1 (Santa Cruz Biotechno- logy, Santa Cruz, CA, USA), IкB $\alpha$, phospho-p65 (Ser536) (Cell Signaling Technology, Beverly, MA, USA), p65 (Upstate Biotechnology, Lake Placid, NY, USA), and actin (Sigma Aldrich, St Louis, MO, USA) were used in this study. HUVECs were purchased from PromoCell (Heidelberg, Germany) and cultured in endothelial cell growth medium supplemented with $5 \%$ (v/v) heat-inactivated $\mathrm{FBS}$ at $37^{\circ} \mathrm{C}$ in $5 \% \mathrm{CO}_{2}$.

\section{Western blot analysis}

Western blot analysis was performed as described previously. ${ }^{9}$ All samples were mixed with sample buffer, boiled for seven minutes, separated by SDS-PAGE under denaturing conditions, and electroblotted to nitrocellulose membranes. All signals were visualized using enhanced chemiluminescence detection reagents and analyzed by densitometric scanning (ChemiDoc XRS Imaging System; Bio-Rad, Hercules, CA, USA). The membranes were reblotted with anti-actin antibody to verify equal loading of protein in each lane.

\section{Quantitative reverse transcription-PCR}

Total RNA from the HUVECs was isolated using the RNeasy mini kit (Qiagen, Hilden, Germany), and first strand of the cDNA was synthesized using a Transcriptor First Strand cDNA synthesis kit (Bio-Rad). Quantitative reverse transcription-PCR was performed using iTaq universal SYBR Green supermix (Bio-Rad) according to the manufacturer's protocol. Primers used were as follows. ICAM-1 sense: 5'- AGG GTA AGG TTC TTG CCC AC -3'; ICAM-1 antisense: 5'- TGA TGG GCA GTC AAC AGC TA-3', VCAM-1
A

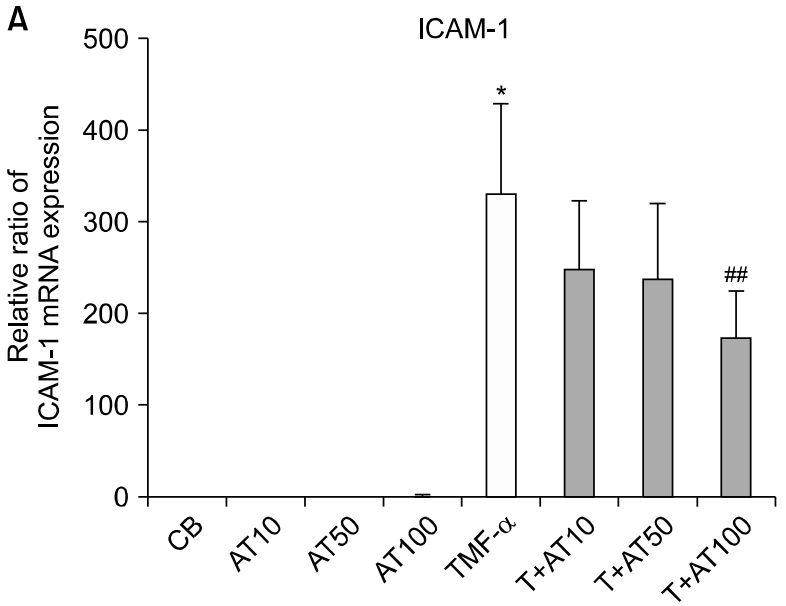

B

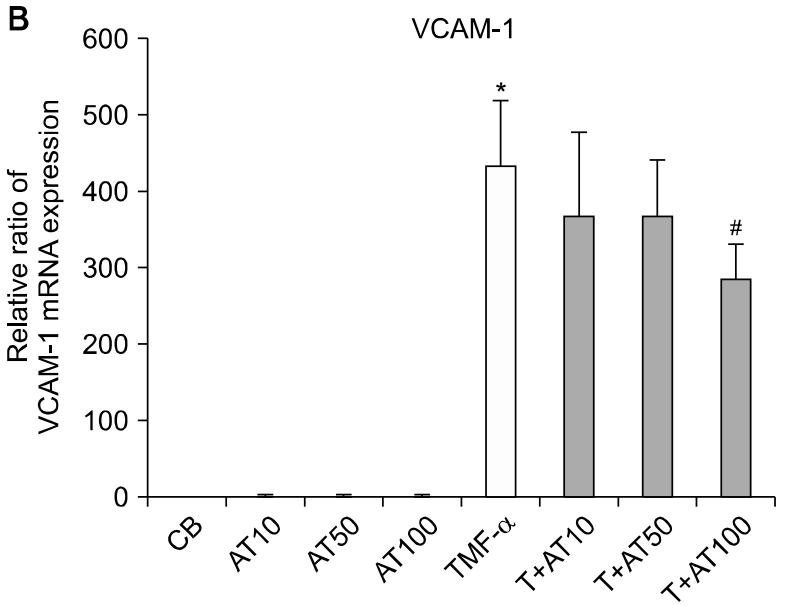

Figure 1. Allium tuberosum (AT) extract reduces mRNA expression of intercellular adhesion molecule (ICAM)-1 and vascular cell adhesion molecule (VCAM)-1 in TNF- $\alpha$-stimulated vascular endothelial cells. Quantitative reverse transcription-PCR analysis of (A) ICAM-1 and (B) VCAM-1 mRNA levels in TNF- $\alpha$-stimulated human umbilical vein endothelial cells (HUVECs) co-treated with the AT extract. HUVECs were pre-treated with 10, 50, and $100 \mu \mathrm{g} / \mathrm{mL}$ AT extract for 30 minutes and exposed to TNF- $\alpha(10 \mathrm{ng} / \mathrm{mL})$ for 4 hours. Control cells (CB) received vehicle alone. ${ }^{*} P<0.001$ vs. $\mathrm{CB} ;{ }^{\#} P<0.05$ vs. TNF- $\alpha ;{ }^{\# \#} P<0.01$ vs. TNF- $\alpha$. 
sense: 5'- GTC TCC AAT CTG AGC AA -3'; VCAM-1 antisense: 5'TGG GAA AAA CAG AAA AGA GGT G -3', GAPDH sense: 5'- TTG ATG GCA ACA ATC TCC AC -3'; GAPDH antisense: 5'- CGT CCC GTA GAC AAA ATG GT -3'.

\section{Monocyte adhesion assay}

THP-1 cells (American Type Culture Collection, Manassas, VA, USA) were incubated with Cell Tracker (Invitrogen, Carlsbad, CA, USA) for 15 minutes at $37^{\circ} \mathrm{C}$. Monocyte-endothelial adhesion was determined by fluorescence labeling of monocytes as described previously. ${ }^{10}$ HUVECs were pre-treated with the AT extract (100 $\mu \mathrm{g} / \mathrm{mL})$ for 30 minutes and stimulated with TNF- $\alpha(10 \mathrm{ng} / \mathrm{mL})$ and AT extract $(100 \mu \mathrm{g} / \mathrm{mL})$ for 4 hours. Fluorescently labeled monocytes were added to the HUVEC monolayer and allowed to adhere for 2 hours. The number of monocytes adhering to the HUVECs is expressed as a percentage calculated using the following formula: percentage adherence $=($ adherent signal/total signal $) \times 100$.

\section{Statistical analysis}

Data are expressed as mean $\pm \mathrm{SD}$. Mean comparisons between two groups were examined for significant differences using
ANOVA, followed by individual comparisons with Tukey's post hoc test, with a $P$-value $<0.05$ considered to indicate a statistically significant difference.

\section{RESULTS}

1. Allium tuberosum extract reduces mRNA expression of intercellular adhesion molecule- 1 and vascular cell adhesion molecule- 1 in TNF- $\alpha$-stimulated vascular endothelial cells

Previous studies have reported that TNF- $\alpha$ stimulates ICAM- 1 and VCAM-1 expression in vascular endothelium. ${ }^{11}$ Pre-treatment with the AT extract $(100 \mu \mathrm{g} / \mathrm{mL})$ and TNF- $\alpha$ decreased ICAM- 1 mRNA levels by approximately $48 \%$ compared with TNF- $\alpha$ alone (Fig. 1A). The AT extract also suppressed TNF- $\alpha$-induced VCAM-1 mRNA levels similarly by $58 \%$ after treatment with the AT extract (Fig. 1B). The AT extract alone did not affect expression of ICAM- 1 and VCAM- 1 . This suggests that the AT extract suppresses TNF- $\alpha$-induced mRNA expression of adhesion molecules in HUVECs.
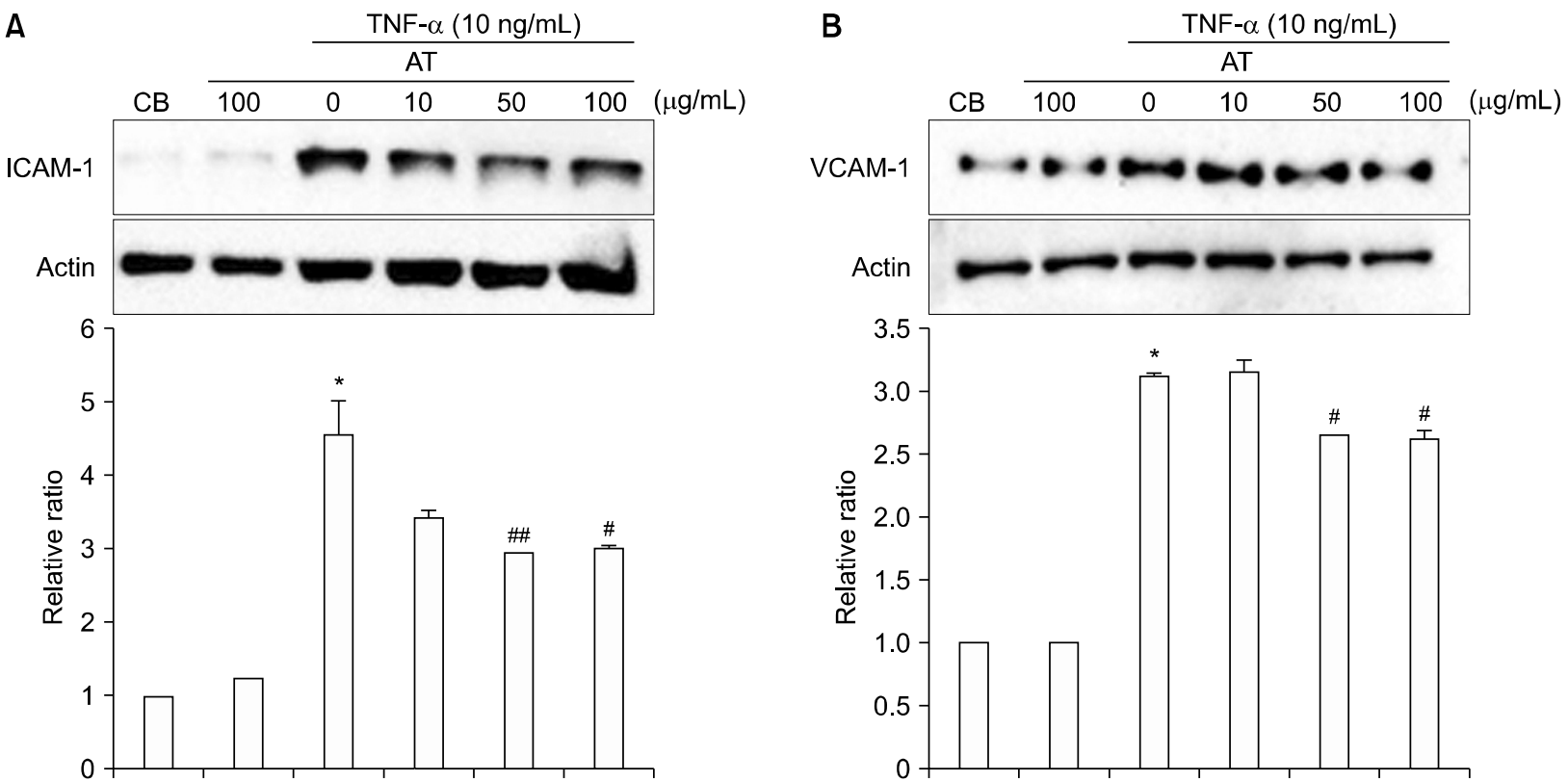

Figure 2. Allium tuberosum (AT) extract attenuates protein expression of intercellular adhesion molecule (ICAM)-1 and vascular cell adhesion molecule (VCAM)-1 in TNF- $\alpha$-stimulated vascular endothelial cells. Immunoblot analysis of (A) ICAM-1 and (B) VCAM-1 protein levels in TNF- $\alpha$-stimulated human umbilical vein endothelial cells (HUVECs) co-treated with the AT extract. HUVECs were pre-treated with the AT extract for 30 minutes and stimulated with TNF- $\alpha(10 \mathrm{ng} / \mathrm{mL})$ and various concentrations of the AT extract. Each lane contains $20 \mu \mathrm{g}$ cellular protein. The blot was probed with anti-ICAM-1 or VCAM-1 antibody (upper panel) and reprobed with anti-actin antibody (middle panel) to confirm equal loading of protein in each lane. Densitometric analyses (lower panel) are presented as the relative ratio of each protein to actin. The relative ratio compared to the control was arbitrarily defined as 1 . Bars represent the mean \pm SD from three different experiments. $* P<$ 0.001 vs. control cells (CB); ${ }^{\#} P<0.05$ vs. TNF- $\alpha$; ${ }^{\# \#} P<0.01$ vs. TNF- $\alpha$. 


\section{Allium tuberosum extract attenuates protein ex-} pression of intercellular adhesion molecule- 1 and vascular cell adhesion molecule- 1 in TNF- $\alpha$-stimulated vascular endothelial cells

Next, we examined whether the AT extract affects the protein levels of ICAM-1 and VCAM-1. The HUVECs were treated with the AT extract in a dose-dependent manner $(10,50$, and $100 \mu \mathrm{g} / \mathrm{mL})$ for 30 minutes with or without TNF- $\alpha$ for 6 hours. Treatment with only TNF- $\alpha$ significantly increased the protein levels of ICAM- 1 and VCAM-1. However, both ICAM-1 and VCAM-1 protein expression were significantly reduced by treatment with the AT extract (50 and $100 \mu \mathrm{g} / \mathrm{mL}$ ) (Fig. 2).

\section{Allium tuberosum extract inhibits TNF- $\alpha$-induced signaling of NF- $\mathrm{kB}$ p65}

We examined the effect of the AT extract on NF- $\kappa$ B signaling by analyzing the level of phospho-p65 with Western blotting. Treatment with TNF- $\alpha$ induced phosphorylation of the p65 subunit of NF- $\kappa B$ (about $\sim 1.4$ fold) compared with control cells (CB). However, treatment with AT extract $(100 \mu \mathrm{g} / \mathrm{mL})$ inhibited the TNF- $\alpha$ induced phosphorylation of the p65 (Fig. 3A).
Immunoblot analyses indicated that stimulation with TNF- $\alpha$ for 4 hours increased rapid degradation of IкB $\alpha$ but treatment with the AT extract $(100 \mu \mathrm{g} / \mathrm{mL})$ restored TNF- $\alpha$-stimulated degradation of $\mathrm{I} \kappa \mathrm{B} \alpha$ in HUVECs (Fig. 3B). These results demonstrate that the AT extract blocks TNF- $\alpha$-induced signaling of NF-kB p65 in vascular endothelial cells.

\section{Allium tuberosum extract blocks adhesion of mo- nocyte to human umbilical vein endothelial cell monolayers}

We examined whether the AT extract decreases adhesion of monocyte to TNF- $\alpha$-stimulated HUVECs via regulation of adhesion molecule expression. THP-1 monocytes were labeled with Cell Tracker and added to confluent monolayers of HUVECs, which were treated with $\mathrm{CB}, \mathrm{AT}$ extract, TNF- $\alpha$, or TNF- $\alpha$ and AT extract $(100 \mu \mathrm{g} / \mathrm{mL})$. TNF- $\alpha$ stimulated HUVECs leaded a dramatic increase in monocyte adhesion compared with $\mathrm{CB}$ treated cells. However, co-treatment with the AT extract $(100 \mu \mathrm{g} / \mathrm{mL})$ decreased monocyte adhesion of HUVECs by $53 \%$ compared to TNF- $\alpha$ treatment. The AT extract alone had no effect on adhesion of monocyte to HUVECs (Fig. 4).

B

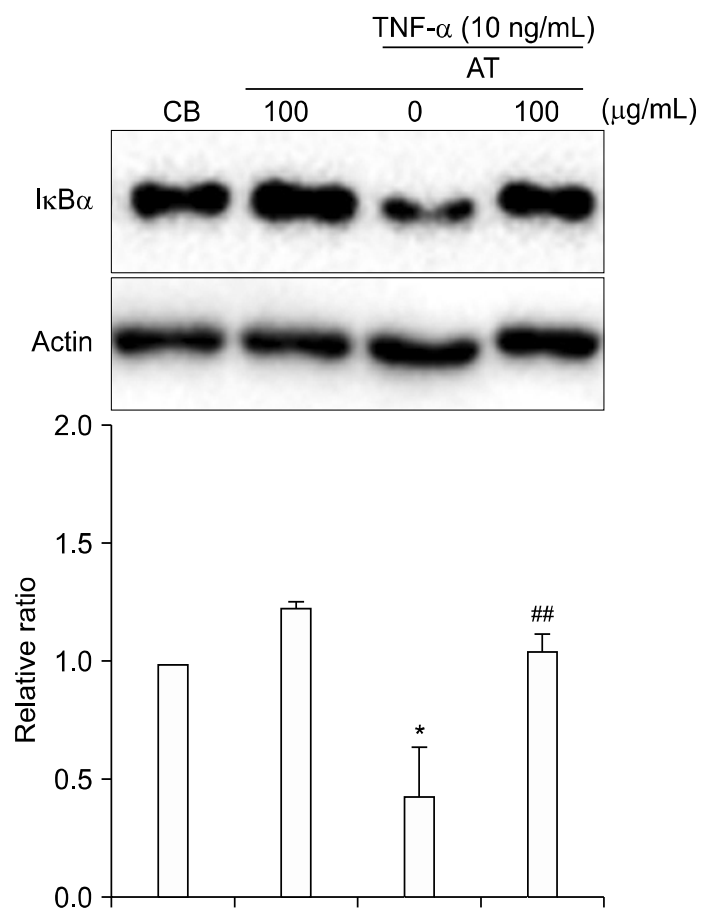

Figure 3. Allium tuberosum (AT) extract inhibits TNF- $\alpha$-induced signaling of NF- $\kappa B$. Immunoblot analysis of (A) phosphorylated p65 subunit

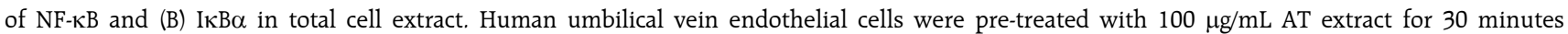
and exposed to TNF- $\alpha(10 \mathrm{ng} / \mathrm{mL})$ for 2 and 4 hours. Total cell extracts were prepared and phosphorylation of p65 and IкB $\alpha$ was analyzed by Western blotting. Densitometric analyses are presented as the relative ratio of phospho-p65 to p65 and that of IkB $\alpha$ to actin. Bars represent the mean $\pm \mathrm{SD}$ from three different experiments. ${ }^{*} P<0.01$ vs. control cells $(\mathrm{CB}) ;{ }^{\#} P<0.05,{ }^{\# \#} P<0.01$ vs. TNF- $\alpha$. 
A

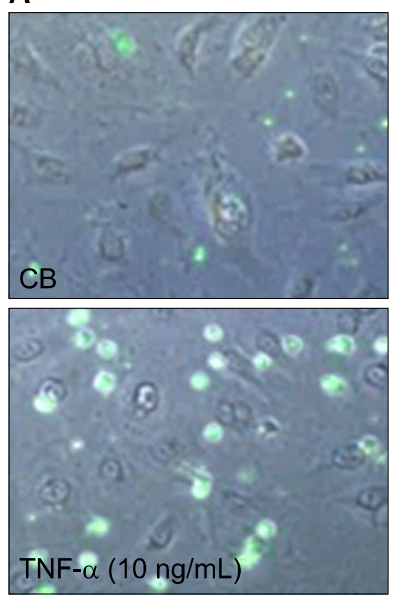

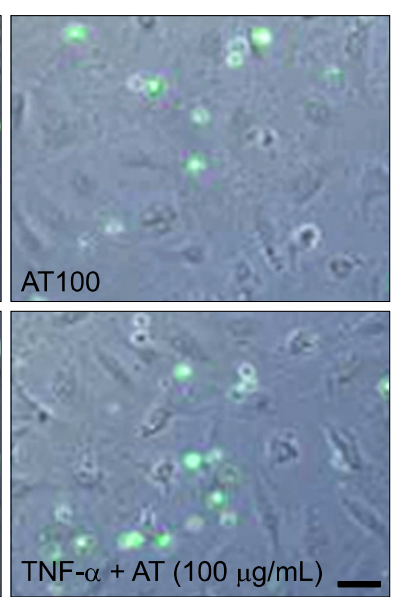

B

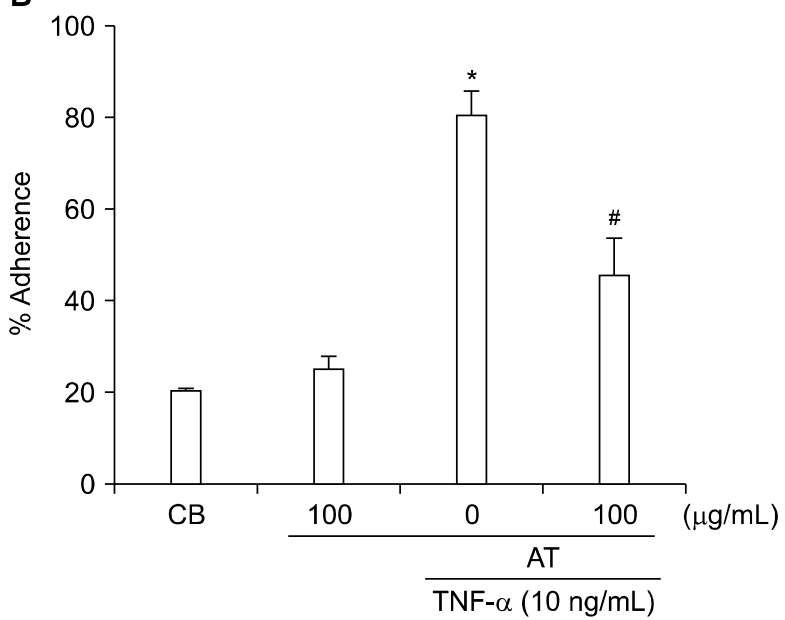

Figure 4. Allium tuberosum (AT) extract blocks adhesion of monocyte to human umbilical vein endothelial cell (HUVEC) monolayers. (A) Representative images of the adhesion of monocytes to HUVEC monolayers. HUVECs were incubated with the indicated AT extract (100 $\mu \mathrm{g} / \mathrm{mL})$ and TNF- $\alpha(10 \mathrm{ng} / \mathrm{mL})$ for 4 hours. Fluorescently labeled monocytes were added to the HUVEC monolayer and allowed to adhere for 2 hours. (B) Quantification of monocyte adhesion to HUVECs. Data from three experiments are expressed as a percentage of adhesion to TNF- $\alpha$-induced HUVECs. Bars represent the mean $\pm \mathrm{SD}$ from three experiments. ${ }^{*} P<0.001$ vs. control cells $(\mathrm{CB}) ;{ }^{\#} P<0.01 \mathrm{vs}$. TNF- $\alpha$.

\section{DISCUSSION}

In our study, we demonstrated that the AT extract reduces TNF- $\alpha$-induced ICAM- 1 and VCAM- 1 expression via regulation of the mechanism of NF- $\mathrm{KB}$ signaling in cultured HUVECs. This result suggests that the AT extract exerts an anti-inflammatory effect, which is mediated by downregulation of adhesion molecule expression. Studies have shown that the AT extract is associated with prevention of atherosclerosis by decreasing body fat and lipid content and improving liver and vascular endothelial cell function based on anti-thrombotic effects and inhibition of high low-density lipoprotein (LDL) oxidation in LDL receptor knockout mice. ${ }^{12}$ Our data support the anti-vascular inflammatory role of the $\mathrm{AT}$ extract in preventing atherosclerosis.

A process of leukocyte adhesion to stimulated endothelial cells is important in acute inflammatory reaction and development of early atherosclerosis. NF- $\mathrm{KB}$ activation participates in the transcription of numerous pro-inflammatory genes, including those encoding vascular cell adhesion regulator. ${ }^{13}$ VCAM-1 mediates the adhesion of monocytes, lymphocytes, and diverse immune cells to the surface of endothelial cells, promoting migration through the endothelium. In this process, the active ingredient in the AT extract inhibited the adherence of leukocytes to adjacent endothelial cells by reducing ICAM- 1 and VCAM- 1 levels. This suggests that the AT extract may regulate the rate of leukocyte recruitment at inflammatory sites.

Atherosclerosis and cancer are related to factors, such as oxidative stress, inflammation, abnormal apoptosis, unregulated cell proliferation, and vascular remodeling in the early and developmental stages. ${ }^{14}$ In the inflammatory reaction, leukocyte migrates to the damaged tissue, and the inflammatory reaction related to the capillary system, including the surrounding connective tissue and immune cells, is induced. In the case of cancer, monocyte-derived macrophages are often found as host cells in tumor and play a role in supporting the factors necessary for the growth of tumors in the stroma, as well as forming a major component of the inflammatory response, including neutrophil, monocyte, endothelial cell, macrophage. Inflammation plays a role in promoting tumor progression. Specifically, VCAM-1 has been shown to play a role in leukocyte extravasation of T-cell immunity against immune evasion in tumors. ${ }^{15}$ The results of this study showed that the AT extract reduced the expression of adhesion molecules, such as VCAM-1 and ICAM-1 in endothelial inflammation and inhibited the adhesion of THP-1 cells to stimulated endothelial cells. It is not only a preventable effect, but also a future-oriented result that can prevent cancer.

In conclusion, our data indicate that the extract of AT reduced TNF- $\alpha$-induced ICAM-1 and VCAM-1 mRNA and protein expression in HUVECs via regulation of the NF-KB signaling pathway. We demonstrated that the AT extract prevents TNF- $\alpha$-induced vascular inflammation and may be potentially used for providing protection against inflammatory diseases. The extract alone or in combination with other factors may impart beneficial effects and play a pivotal role in vascular diseases, such 
as hypertension, systemic inflammation, and oxidative stress. Functional components of the AT extract can be expected to become an important role in the prevention of early atherosclerosis.

\section{ACKNOWLEDGMENTS}

This work was supported by the Korea Food Research Institute, and National Research Council of Science and Technology (NST) grant by the Korea government (MSIP) (No. CAP-15-09-KIMS).

\section{CONFLICTS OF INTEREST}

No potential conflicts of interest were disclosed.

\section{REFERENCES}

1. Han SH, Suh WS, Park KJ, Kim KH, Lee KR. Two new phenylpropane glycosides from Allium tuberosum Rottler. Arch Pharm Res 2015:38:1312-6.

2. Zeng Y, Li Y, Yang J, Pu X, Du J, Yang X, et al. Therapeutic role of functional components in alliums for preventive chronic disease in human being. Evid Based Complement Alternat Med 2017;2017:9402849.

3. Sprague AH, Khalil RA. Inflammatory cytokines in vascular dysfunction and vascular disease. Biochem Pharmacol 2009;78:539-52.

4. McHale JF, Harari OA, Marshall D, Haskard DO. Vascular endothelial cell expression of ICAM-1 and VCAM-1 at the onset of eliciting contact hypersensitivity in mice: evidence for a dominant role of TNF-alpha. J Immunol 1999; 162:1648-55.

5. Chan SC, Shum DK, Tipoe GL, Mak JC, Leung ET, Ip MS.
Upregulation of ICAM-1 expression in bronchial epithelial cells by airway secretions in bronchiectasis. Respir Med 2008;102: 287-98.

6. Abraham E, Singer M. Mechanisms of sepsis-induced organ dysfunction. Crit Care Med 2007;35:2408-16.

7. Arango Duque G, Descoteaux A. Macrophage cytokines: involvement in immunity and infectious diseases. Front Immunol 2014:5:491.

8. Hofmann S, Grasberger H, Jung P, Bidlingmaier M, Vlotides J, Janssen $\mathrm{OE}$, et al. The tumour necrosis factor-alpha induced vascular permeability is associated with a reduction of VE-cadherin expression. Eur J Med Res 2002;7:171-6.

9. Ahn SY, Cho CH, Park KG, Lee HJ, Lee S, Park SK, et al. Tumor necrosis factor-alpha induces fractalkine expression preferentially in arterial endothelial cells and mithramycin A suppresses TNF-alpha-induced fractalkine expression. Am J Pathol 2004;164: 1663-72.

10. Moon SO, Kim W, Sung MJ, Lee S, Kang KP, Kim DH, et al. Resveratrol suppresses tumor necrosis factor-alpha-induced fractalkine expression in endothelial cells. Mol Pharmacol 2006;70: $112-9$.

11. Bernot D, Peiretti F, Canault M, Juhan-Vague I, Nalbone G. Upregulation of TNF-alpha-induced ICAM-1 surface expression by adenylate cyclase-dependent pathway in human endothelial cells. J Cell Physiol 2005;202:434-41.

12. Kwon OJ, Lee JY, Roh SS. Prevention effect of Allium tuberosum extract on ateriosclerosis in LDL receptor knockout mouse. Korean J Herbol 2016;31:13-9.

13. De Martin R, Hoeth M, Hofer-Warbinek R, Schmid JA. The transcription factor NF-kappa B and the regulation of vascular cell function. Arterioscler Thromb Vasc Biol 2000;20:E83-8.

14. Tapia-Vieyra JV, Delgado-Coello B, Mas-Oliva J. Atherosclerosis and cancer; a resemblance with far-reaching implications. Arch Med Res 2017;48:12-26.

15. Wu TC. The role of vascular cell adhesion molecule-1 in tumor immune evasion. Cancer Res 2007;67:6003-6. 